\title{
An integrative review of the cognitive costs and benefits of note-taking
}

Renée S. Jansen ${ }^{\mathrm{a}, 1}$ (corresponding author)

R.S.Jansen@uu.nl

Daniel Lakens $^{\mathrm{a}}$

D.Lakens@tue.nl

Wijnand IJsselsteijn ${ }^{\mathrm{a}}$

W.A.IJsselsteijn@tue.nl

${ }^{a}$ Eindhoven University of Technology

Human-Technology Interaction

P.O Box 513

5600 MB Eindhoven

The Netherlands

${ }^{1}$ Present address

Utrecht University

Department of Education

Heidelberglaan 1

3584 CS Utrecht

The Netherlands

$$
======+ \text { PLEASE NOTE }=======
$$

This is not the final version. The final peer-reviewed version has been published in Educational Research Review with doi:10.1016/j.edurev.2017.10.001. To cite, cite the version in ERR, NOT this pre-print version.

List of most important changes made:

- Definition of research aim and research questions in the Introduction.

- Explanation of the origination of the analytic criteria in the description of the literature review.

- Shortening of the sections on lecture speed, individual differences, and type of questions.

- Addition/rewriting of concluding paragraph for lecture speed, structure of lecture material, note-taking style, and structure of note-taking.

- Inclusion of several recent articles: Svinicki (2017), Reed, Rimel, and Hallett (2016), Olive and Barbier (2017).

$$
=\mathrm{e}=\mathrm{=}=\mathrm{=}=\mathrm{=}=\mathrm{=}=\mathrm{=}=\mathrm{=}=\mathrm{=}=\mathrm{=}=
$$


Abstract. Students frequently engage in note-taking to improve the amount of information they remember from lectures. One beneficial effect of note-taking is known as the encoding effect, which refers to deeper processing of information as a consequence of taking notes. This review consists of two parts. In the first part, four lines of research on the encoding effect are summarized: 1) manipulation of the lecture material, 2) manipulation of the method of notetaking, 3) the importance of individual differences, and 4) the testing procedure used in the empirical studies. Our review highlights the fragmented nature of the current literature. In the second part of this review we distinguish five forms of cognitive load that are induced by notetaking. Cognitive load theory is used to integrate the divergent results in the literature. We conclude that cognitive load theory provides a useful framework for future theory development and experimental work.

Keywords. Cognitive load, encoding effect, note-taking, memory, information processing. 


\section{An integrative review of the cognitive costs and benefits of note-taking}

The density of information presented to students increases as they proceed from primary school to secondary school to university. Students are required to comprehend and acquire more information in the same amount of time. To cope with this increasing demand on their information-processing capabilities, students frequently engage in note-taking to improve how much information they remember (Christopoulos, Rohwer, \& Thomas, 1987). For decades, notetaking has been an analogue activity, with students taking notes using pen and paper (i.e. longhand note-taking). The increasing availability of portable electronic devices has changed the way in which students take their notes. Longhand note-taking is now considered 'traditional' note-taking (Lin \& Bigenho, 2011; Reimer, Brimhall, Cao, \& O’Reilly, 2009), while typing is a more modern form of note-taking.

Memory benefits of note-taking have been classified into two groups (Di Vesta \& Gray, 1972). On the one hand, note-taking offers long term benefits by having notes available for review and rehearsal. This is known as the external storage effect of note-taking. On the other hand, note-taking offers immediate benefits as students taking notes engage in a deeper level of processing. This is known as the encoding effect of note-taking. The beneficial effects of notetaking have been well-established (e.g. Barnett, Di Vesta, \& Rogozinski, 1981; Carter \& Van Matre, 1975; Weiland \& Kingsbury, 1979). Kiewra (1987, 1989) integrated these studies and distilled several factors influencing these effects. In recent years, laptop note-taking and video lectures have become increasingly popular. Many new studies have been performed, but the results from these studies are frequently in disagreement. An integrative review on the encoding effect of note-taking is therefore both timely, and necessary in order to help guide future studies aiming to address current discrepancies in the literature. 
In the first part of this review we summarize four lines of research. First, we review studies that have manipulated aspects of the lecture material presented, such as its format (e.g. audio or video lectures). Second, we review studies that manipulated the way in which participants took notes (e.g., by hand or typing). Third, we review studies that measured individual differences, such as cognitive ability, and related those to the effects of note-taking on post-test performance. Finally, we review studies that examined the influence of the testing procedure used.

In the second part of this review we highlight how many of the variables that are shown to influence the encoding effect in note-taking influence the cognitive load experienced by the notetaker. This suggests there is an important role for cognitive load when modelling the effect of note-taking on memory performance. We distinguish five forms of cognitive load that are induced when taking notes while comprehending a lecture, and link the four lines of research reviewed in the first part of this article to one or more types of cognitive load that are induced. By reviewing and integrating literature in this way, we arrive at an explanatory framework that allows us to better understand the current discrepancies in empirical evidence on the encoding effect, and provides useful pointers towards future research.

\section{Literature Review}

A literature search was conducted for studies exploring the effect of note-taking on memory for lecture content. The search query consisted of two components, one focussing on note-taking and the other on memory. The exact search term used was (note-taking OR (taking note*) OR (note* taking) OR notetaking) AND (memory OR performance OR achievement OR knowledge OR remembrance OR remember*). This search was conducted on October 4th 2016 in the Scopus database resulting in 467 hits and in the PsycInfo database resulting in 454 hits. Titles 
and abstracts of the results were scanned for suitability for the current study. The focus of this paper is on empirical studies of the encoding effect. Therefore, papers had to include at least two experimental conditions without note review, and a memory measure for the lecture content. The study had to be conducted in an educational setting (e.g., note-taking during law trials was excluded) and the literature search was restricted to articles in English. Articles that focused on collaborative note-taking or on a special population of students (e.g., students with disabilities, mental disorders) were excluded. After filtering the results from the database, we used snowballing to identify relevant studies that were not part of the corpus resulting from our search query. See Appendix A for an overview of the studies included in this review.

\subsection{Lecture characteristics}

When examining effects of lecture characteristics on the relationship between note-taking and memory performance, three important lecture characteristics can be identified: the modality in which information is presented, lecture speed and lecture structure.

2.1.1. Modality of lecture material. Lecture modality concerns the way in which a lecture is presented, this can be either written or spoken. Spoken lectures can furthermore be presented with audio only, with a video lecture or with a live lecture. Modality may influence memory as one can take notes parallel with note-taking for text, but not for spoken lectures. In a study conducted by Peters (1972), participants were presented with a 1,613 word lecture. The lecture was presented either in written form, spoken at $146 \mathrm{wpm}$, or spoken at $202 \mathrm{wpm}$. Participants were randomly distributed over these three conditions. Furthermore, for each modality half of participants was allowed to take notes while the other half of participants was not allowed to take notes. After the lecture, memory for the lecture content was measured with a 25-item 5-alternative multiple choice test. There was a main negative effect of note-taking, as those who took notes performed worse on the multiple choice test than those who did not take 
notes. There was no main effect of modality, nor did modality interact with note-taking. Given the small sample size, this suggests that the modality of the lecture does not have a large effect on the effect of note-taking for memory of the lecture content. Follow-up research by Peper and Mayer (1978, study 2) also studied the potential influence of lecture modality on the effect of note-taking on memory for lecture content. Forty-eight participants either watched a 22 minute video or read a transcript of this video (i.e. modality manipulation). During this lecture, half of participants were allowed to take notes, while the other half was not. Afterwards, participants' memory for the lecture content was measured with 12 open-ended questions. In line with Peters (1972), no main effect of lecture modality was observed. They did however find a main effect of note-taking, which surprisingly was in the opposite direction as observed by Peters (1972). Notetaking led to better performance in the memory task, regardless of the modality in which the information was presented. A study by Schoen (2012) followed a $2 x 2$ design, where participants $(n=72)$ watched or read lecture materials, either by watching a 16.5 minute recorded lecture, or by reading eight textbook pages (which took approximately 20 minutes to read). The information in the lecture was almost identical to the information in the textbook; only transitions were added between sections to create a smooth lecture. Participants were further assigned to either laptop note-taking or to longhand (i.e., handwriting) note-taking. Participants' memory for the lecture content was measured with eleven MC questions and two fill-in-the-blank questions. While lecture time was different between modalities, no main effect was found of lecture modality on memory performance. Thus, either time did not matter for lecture retention or a video lecture is potentially a more efficient method for transferring lecture content than a text. A main effect of note-taking style was observed (laptop vs. longhand), with laptop note-taking leading to better performance on the memory test than longhand note-taking. The effect of note-taking style on 
memory for lecture content will be discussed in more detail in the section on methods of notetaking.

Overall, based on the available research, there is no indication that lecture modality influences the amount of lecture material students remember, nor is there any indication modality effects depend on whether students take notes or not. This is interesting, as it would appear that note-taking based on a text is easier than taking notes when listening to a lecture. After all, when reading lecture material, no new material is presented while turning away from the text to take notes, while during a video or audio lecture new material is presented while students take notes. Even though existing studies reveal no evidence for an effect of lecture modality, we need to be cautious with this conclusion. The low statistical power in many of the studies, and the plausibility of an inference effect, warrants future research with larger samples.

2.1.2. Lecture speed. When the lecture modality is spoken word (either live or video), the speed of the lecture becomes important. If the video or audio lecture is presented at higher speed, more information is presented in the same amount of time. Aiken, Thomas, and Shennum (1975) examined the effects of note-taking and lecture speed on memory performance. Participants $(n=$ 180) were presented with an audio lecture that was cut into four segments. Participants were randomly assigned to one of three lecture speed conditions: The lecture was presented once at normal speed, once at double speed, or twice at double speed. Within each lecture speed condition participants were randomly assigned to one of three note-taking conditions: No notetaking, note-taking while listening to the lecture, or spaced note-taking. In the last condition, participants took notes during breaks between lecture segments. These breaks were equal in length to the preceding segment; roughly four minutes. Total time was equated between conditions. While participants in the spaced note-taking condition took notes during the lecture breaks, participants in the other two conditions performed a letter cancellation task during these 
breaks. In this task, participants had to mark specific letters in an unrelated piece of text. Participants were tested on their memory for the lecture content with a free recall test, a test in which they had to write down all they could remember, in addition to having to identify which of 70 factually correct statements actually came from the lecture.

Results on both memory tests showed the same pattern of results. Main effects were found for both lecture speed and note-taking condition. Memory performance was worse in the once speeded condition, while performance was equivalent in the normal speed and twice speeded conditions. The main effect of note-taking condition indicated that spaced note-taking was superior both to parallel note-taking and to no note-taking. However, in the latter two conditions participants were given a letter cancellation task during the lecture breaks, while participants in the former condition were allowed to take notes during this time. We do not consider this a fair comparison of note-taking conditions for two reasons. First, participants that had to perform the letter cancellation tasks had to switch their attention. This switching likely increased the complexity of the task. Furthermore, participants in the spaced note-taking condition were given the opportunity to think about and rehearse the lecture content during the lecture breaks, while participants in the other two conditions were not given this opportunity. Participants should have been provided equal time with the lecture material.

When comparing the studies described above, it becomes clear that lecture modality does not have an effect on memory performance (Peters, 1972; Peper \& Mayer, 1972, study 2; Schoen, 2012), as long as students are given enough time with the lecture material (Aiken et al., 1975). The effect of note-taking on memory performance differs widely between studies. Peters (1972) observed a negative effect of note-taking, Peper \& Mayer (1972, study 2) observed a positive effect, and Aiken et al. (1975) found no difference between parallel and no note-taking conditions. No interaction effect between lecture modality and note-taking was observed that 
could explain these differences. However, several differences in the experimental designs used in these studies may explain the different results, such as differences in difficulty of lecture material, differences in the type of lecture material (i.e., audio or video), differences in the length of lecture material, and differences in the memory tests used as dependent variable.

2.1.3. Structure of lecture material. In addition to lecture modality, the structure (how well different parts of a lecture are connected to each other) of the lecture may influence the relationship between note-taking and memory for lecture content. Di Vesta and Gray (1973) compared lectures that varied in how thematically related different lecture segments were. In the first experiment, participants $(n=90)$ were presented with a 30 minute audio lecture that was divided into six segments. The segments were either continuously thematically related (all segments were related to the same superordinate topic and each segment was related to the previous segments), discontinuous but thematically related (all segments were related to the same superordinate topic, but there was no connection between segments), or discontinuous and not thematically related. Furthermore, half of the participants in each condition were allowed to take notes, while the other half was not allowed to take notes. Intuitively, one would expect participants to remember the content of the segments best in the continuously thematically related condition. However, on a true/false test, no main effect of lecture structure was observed. On a free recall test, a surprising main effect of lecture structure was found, such that performance on the free recall test was best in the discontinuous and not thematically related condition, followed by the discontinuous but thematically related condition, with the continuously thematically related condition leading to the worst performance. There also was a main effect of note-taking, with participants in the note-taking condition scoring better on the free recall test than participants in the no note-taking condition. 
In a second experiment $(n=240)$, the same conditions were tested, now with the addition of a continuous scrambled condition (with the same clips as the continuously thematically related condition, but segments presented in a randomized order). Memory for lecture content was again tested with a free recall test and a true/false test, and performance was again better for those that had taken notes during the lecture. The pattern for the lecture structure conditions exactly replicated the pattern found in the first experiment. Results for the continuous scrambled condition were found to be in between the discontinuous but thematically related and continuously thematically related conditions. Results from these experiments thus indicate that structuring a lecture leads to worse memory performance. This is not in line with intuitive judgment and the authors could only speculate about the possible cause. They argue that the lectures in the continuously thematically related condition were more difficult, as there was more time spend on a single topic. Further research seems warranted.

Another way to structure a lecture is by providing students with organizational cues during the lecture. Half of the participants (total $n=60$ ) in the study by Titsworth and Kiewra (2004) were presented a structured audio lecture, with clear organizational keywords (e.g. "we will describe four theories, for each theory we will describe five aspects"). The other half of participants were presented the same audio lecture, but without the organizational keywords. Cueing was found to have a large effect both on students' understanding of the lecture structure, and on their memory for the details presented in the lecture.

\subsection{Method of note-taking}

2.2.1. Note-taking style. Note-taking style, or the manner in which notes are taken, has also been varied in experiments exploring the relationship between note-taking and memory for lecture content. The most common note-taking styles are taking notes by hand or typing them on 
a computer. The available evidence suggests laptop note-taking outperforms written note-taking as it is usually faster, allowing students to more quickly focus on the lecture after taking notes.

Already briefly discussed before, Schoen (2012) observed a main effect of note-taking style, where laptop note-taking led to better performance on the memory test compared to longhand note-taking. Schoen (2012) also observed an interaction effect, which showed the best performance when typing notes during a lecture and the worst performance when taking longhand notes during a lecture. When the lecture material was presented as text, there was no difference in memory performance between note-taking styles. A potential explanation for this interaction effect is that when taking notes from written text, no new information is presented during note-taking. When taking notes during a video lecture, new information is presented while taking these notes. Students must thus divide their attention across listening to the lecture and writing their notes. Furthermore, since people can take notes faster typing than writing (Graham, Berninger, Weintraub, \& Schafer, 1998; Pereira et al., 2013), the speed with which people can take notes matters more when taking notes during a video lecture. Given the speed benefit of laptop note-taking, laptop note-taking may thus be the best note-taking style to deal with the requirement of parallel note-taking during a video lecture. Results of a study by Bui, Myerson and Hale (2013, study 1$)$ provided similar conclusions. Participants $(n=80)$ were presented a short audio lecture based on a nonfiction book. They were randomly assigned to either a longhand note-taking condition or a computer note-taking condition. Their memory for the content of the audio lecture was tested both with a 10 minute free recall test, in which they were asked to write down all they could remember, and a short answer test consisting of 18 openended questions that required a single sentence answer. On both measures, computer note-taking led to better performance compared to longhand note-taking. 
The observed better memory performance for the lecture content after typing notes is contradictory to the results of a recent study by Mueller and Oppenheimer (2014). They conducted two experiments ( $n=65$ and $n=149$ ) in which memory for the content of a TEDx talk was measured. Participants either took computer notes or longhand notes while watching one of five 15-minute TEDx talks. Afterwards they were tested with an unknown number of factualrecall and conceptual-application questions. In both experiments, participants' performance on the conceptual questions was better in the longhand notes condition compared to the computer notes condition. Performance on the factual questions showed a trend towards better performance with longhand note-taking.

While Schoen (2012) and Bui and colleagues (2013) found support for a benefit of computer note-taking over longhand note-taking, Mueller and Oppenheimer (2014) observed the opposite pattern. This could potentially be explained by the fact that the TEDx clips used by Mueller and Oppenheimer (2014) may have been less informationally complex than the lecture and nonfiction material used by Schoen (2012) and Bui and colleagues (2013). In the latter two studies, more new information may have been presented while participants were taking notes than in the former study. This does however not explain why there was a beneficial effect of longhand note-taking compared to computer note-taking in Muller and Oppenheimer (2014). We will return to some possible explanations for this finding when we discuss the effects of cognitive load.

2.2.2. Structure of note-taking. Most empirical studies on the effect of note-taking on memory performance have not given participants' specific instructions how to structure notes. Some experiments have however directly manipulated the structure of the notes participants made. Participants were for instance instructed to take organised notes, in which they had to paraphrase and organise as much of the information as possible. This appears to be the best note- 
taking strategy, except when material is complex. Bui and colleagues (2013) conducted three experiments in which all participants took notes during an 11 minute audio lecture. Participants ( $n=80, n=76$, and $n=76$ ) were instructed to either take organised notes or to transcribe the lectures by recording as much of the information as possible in their notes. Memory for the lecture content was tested with a free recall test and a short answer test in all three experiments. Results consistently indicated better memory performance with transcribed notes compared to the organised note-taking condition. It therefore appears more important to write down as much information as possible, than to organise the information.

Structure of taking notes was also manipulated in a study by Bretzing and Kulhavy (1979). Participants $(n=180)$ read a 2,000 word text and were randomly assigned to one of five conditions in which in three conditions the structure of the notes participants took was manipulated. Participants were instructed to summarise, paraphrase, or literally copy (i.e., verbatim) important sentences. In two control conditions, participants were asked to read the text while circling all words that started with a capital letter, or just to read. Memory for the content of the text was tested with 25 short-answer questions requiring participants to combine the facts presented in the text. Summarisation and paraphrasing led to the best performance on this memory task, followed by verbatim copying of sentences, or simply reading the text. These four conditions all led to better performance than searching for words starting with a capital letter. While Bui and colleagues (2013) and Bretzing and Kulhavy (1979) both examined the effects of note-taking structure on memory for lecture content, it is difficult to directly compare their results. They did not use the same manipulations of note-taking structure, and therefore we can only compare the best matching (but not identical) conditions. The organised note-taking condition used by Bui and colleagues (2013) is most similar to the summarised note-taking condition used by Bretzing and Kulhavy (1979). The transcribe note-taking condition of Bui and 
colleagues (2013) is most similar to the verbatim copying of sentences condition used by Bretzing and Kulhavy (1979). These comparisons yield divergent results. Bretzing and Kulhavy (1979) found summarisation to be better than copying, while Bui and colleagues (2013) found copying (i.e. transcribing) to be better for memory. We hypothesize that lecture format may explain these differing results. While Bui and colleagues used an audio lecture, Bretzing and Kulhavy used a text to present the lecture material. Participants in the study by Bretzing and Kulhavy (1979) could read back and forth in the text, allowing them to comprehend the text and extract the most important points sequentially. Participants in the studies by Bui and colleagues were presented with a video, not enabling them to go back and forth through the lecture. They had to summarise the content while comprehending the lecture. Comprehending, selecting the main points, and noting them down simultaneously might have been too challenging. Further research is needed to test this hypothesis and to gain more insight into the influence of the structure of note-taking on the relationship between note-taking and memory.

Bui and colleagues (2013) and Bretzing and Kulhavy (1979) instructed students on the structure of their notes. Peverly and colleagues (2013) took this idea a step further and forced students to adopt a specific note-taking structure. All their participants $(n=204)$ took notes during a 23 minute video lecture. Note-taking structure was manipulated by providing half of the participants with an outline with (sub)headings. The other half of the participants was not given an outline. After the lecture, participants were given 15 minutes to write a summary of the lecture. Students who were provided with the outline wrote more inclusive summaries than the students that were not provided with the outline. The outline thus helped students better remember the lecture content. Kauffman, Zhao, and Yang (2011) also explored the effect of providing participants with an outline in two studies. Participants ( $n=30$ and $n=119)$ were divided over three note-taking structuring conditions. Participants were either given a list-like 
outline with headings and subheadings - as in the study conducted by Peverly and colleagues (2013), a list-like outline with headings only, or an outline in matrix format with headings and subheadings. Participants read a text about several animals and had to note for instance physical features and hunting habits. With the list-like outline with subheadings, separate, labelled text boxes were given for each aspect for each animal. Students that were given only the headings were provided with a single labelled text box per animal. Participants in the matrix note-taking condition were given a matrix with text boxes. The rows were labelled with important aspects and the columns with the different animals. Afterwards, participants' declarative knowledge was tested. Results of both studies indicated that knowledge was best after taking notes with the matrix template. Knowledge performance did not differ between the outline and conventional note-taking structure conditions. Not only the presence of an outline thus seems to be of importance (cf. Peverly et al., 2013), but also the format of the outline.

Bui and McDaniel (2015) also found that the format of the outline matters. They compared memory for the content of a 12 minute audio lecture between students that got a listlike outline, an illustrative diagram of the lecture content, and a control group. Afterwards, participants were tested with a free recall test and a short answer test. On the free recall test, both the diagram and the outline group outperformed the control group. On the short answer test, the diagram group scored best, followed by the outline group, and then the control group. These conditions however did not only differ in the structure of note-taking, but also in the completeness of information provided, as the illustrative diagram contained more information than the outline.

This effect is further explored by Katayama and Robinson (2000). They studied the effects of note-taking structure with a 2 (i.e. structure of outline) x 3 (i.e. completeness of notes) design. The structure of the outline provided to participants $(n=117)$ was a matrix or list-like. 
This outline was provided to students either empty, partially filled, or completely filled. The dependent variable consisted of performance on factual questions, and application questions. No main effect of the structure of the outline was found on either the factual or the application memory test. A main effect of completeness of notes was only found on the application test, with participants provided with complete notes performing worse than those who had been provided with a partially filled or empty outline. The lack of a main effect of note-taking structure is contradictory to the results found by Peverly and colleagues (2013), but may be due to the long period of time participants were allowed to work with the lecture material in the study by Katayama and Robinson (2000). Participants were given 40 minutes to read the 3,500 word text and take notes, after which they were given another 40 minutes to read and study their notes. With such a long time to take and complete notes, the benefit of the matrix format of the outline on memory performance might disappear.

A final way to examine the influence of the structure of notes is by providing students with access to full notes before, during, or after the lecture. These notes are known as lecturer's notes. As participants no longer take notes themselves in these studies, they are outside the scope of this literature review. We do however want to mention that the effect of lecturer's notes on memory performance has been investigated in several studies (e.g. Fisher \& Harris, 1973; Katayama \& Robinson, 2000; Kiewra, 1985; Peper \& Mayer, 1978, study 1). Results suggest that lecturer's notes provide a benefit for memory when compared to no note-taking. However, the best option to improve memory performance still appears to be note-taking, and subsequently reviewing the notes before a test.

2.2.3. Note content. After reviewing aspects of the task that influence memory performance after note-taking, we now turn to studies that examine the relation between the characteristics of the notes taken by participants and participants' recall performance. Several 
note characteristics have been defined in empirical studies, including note quantity, note quality, and verbatim overlap. Before reviewing the studies analysing the influence of note characteristics on memory for lecture content, we will first introduce these measures.

Note quantity is the number of words of the notes that are written down by the participant. Note quality is measured by counting the number of propositions present in the participant's notes. A proposition is a factual statement that can be judged as either right or wrong. To measure note quality, a list of propositions present in the lecture is constructed. This list is then compared to the propositions present in the participant's notes. A higher number of propositions present in the notes is considered to signal better note quality. The exact measure of note quality differs somewhat between the studies discussed hereafter. We therefore advice interested readers to consult the referenced articles for more information about the specific measure of note quality used. Verbatim overlap is a measure of the word-for-word overlap between the lecture content and the content of the notes. Greater verbatim overlap is supposed to lead to lower test performance, as it allows shallower processing of the information than notes wherein participants paraphrase the information while taking notes.

A large number of studies has explored the effects of note quality on memory for lecture content (Aiken et al., 1975; Einstein, Morris, \& Smith, 1985, study 2; Fisher \& Harris, 1973; Kiewra \& Benton, 1988; Kiewra, Benton, \& Lewis, 1987; Peverly et al., 2007, 2013; Peverly \& Sumowski, 2012). These studies have consistently shown that better note quality is related to better performance on memory tests administered afterwards. Lecture formats used in these studies include text, audio, video, and live lecture. Memory for lecture content was in most cases tested with a free recall or summary writing test, but some studies used factual multiple choice questions or fact recognition questions (i.e. true or false). See Table 1 for which format and memory test is used in each study. This line of research points towards a stable relationship 
between note quality and memory for lecture content. Not just quality, but also note quantity matters. There is a positive relationship between note quantity and memory for lecture content (Kiewra \& Benton, 1988; Mueller \& Oppenheimer, 2014; Peverly et al., 2007). Different tests were used to measure memory for lecture content, such as factual-recall questions, conceptualapplication questions, and free recall tests (see Table 1). To conclude, when participants make notes of higher quality, and when participants write down more notes, memory performance is better. It's noteworthy that in the study by Mueller and Oppenheimer (2014) participants did not review their notes. Thus this effect is present even when participants are not given the opportunity to rehearse their notes before a test. This in line with the idea of an encoding effect described by Di Vesta and Gray (1972) which states that taking notes is beneficial for memory performance due to the deeper processing of information, even when the notes are not reviewed.

In addition to note quantity and note quality, Mueller and Oppenheimer (2014) also explored the effects of verbatim overlap in their three studies ( $n=65, n=149$, and $n=109)$. In all three studies, all participants took notes, either by hand or with a computer. These notes were scored on their verbatim overlap. Verbatim overlap was consistently found to have a negative relationship with performance on the factual-recall and the conceptual-application questions presented to the participants, in line with the idea that a higher level of verbatim overlap implies less processing of the information presented.

Overall, these studies show that the characteristics of the notes taken during the lecture presentation influence the performance of the participants on the memory test administered afterwards. Several studies have explored if the information that is present in the notes is actually remembered better than the information that is not noted down. This was indeed found to be true. Aiken and colleagues (Aiken et al., 1975) $(n=180)$ found that the probability of a proposition being recalled was much higher for propositions included in the participant's notes (i.e. 47\%) 
than for propositions not present in the participant's notes (i.e. 12\%). Einstein and colleagues (1985, study $1, n=48)$ made the same comparison and found similar percentages (i.e. $44 \%$ vs. $6 \%$ recall). Peper and Mayer (1986, study 2 ) extended this by showing that incorporating propositions in notes is also important when being tested with a fact retention test. Participants $(n$ $=89$ ) in their study watched a 23 minute lecture and were afterwards tested with factual retention questions. The probability of answering a question correctly when the proposition was present in the notes was $90 \%$, while it was only $36 \%$ when the proposition was not incorporated in the participant's notes. Based on these studies, we can conclude that in addition to the structure of the notes, and the characteristics of the lecture, the content of the notes taken also strongly determines the effect of taking notes on memory.

\subsection{Individual differences}

Up until now, memory performance as a function of note-taking has been regarded to be similar for all participants. We however know that individual differences can influence memory (Daneman \& Carpenter, 1980; Just \& Carpenter, 1992). Peverly (2006) for instance argues that higher handwriting speed is associated with better memory for lecture content as faster notetaking allows students to take better notes and more quickly fully focus on the lecture.

Furthermore, Shrager and Mayer (1989) showed 60 college students an 11 minute video lecture. They found note-taking during the lecture only to be beneficial for those with low prior knowledge. Scores for those students with high prior knowledge did not differ between the notetaking and the no note-taking conditions.

Another individual difference characteristic of which the influence on note-taking has been explored is structure building ability (Bui \& McDaniel, 2015). After listening to a 12 minute audio lecture and performing a free recall and a short answer test, participants' structure building ability was tested. Higher scores on this test indicate a greater ability to create good mental 
models. Analysis indicated a main effect of structure building ability, showing that participants with a high score performed significantly better on both the free recall test and the short answer test.

2.3.1. Cognitive ability. Whereas these individual differences have only been explored in a limited number of studies, a wider range of studies is available on the influence of cognitive ability on the encoding effect. Peper and Mayer (1978) focused on participants' math ability in their studies ( $n=60$ and $n=48$ ). All participants watched a video lecture after which they were asked 6 factual questions and 6 interpretation questions. After participating, students were classified as either high or low math ability based on their already known MSAT (Mathematical Scholastic Aptitude Test) score. Analyses indicated note-taking to be beneficial for all participants when looking at performance on the interpretation questions. Performance on the factual questions was however only higher after note-taking for those with high math ability. From the group of students with low math ability, those that had not taken notes performed better on the factual questions than those that had taken notes during the video lecture.

Other studies have focused on the benefit of working memory ability. In two experiments conducted by Berliner (1971) (both $n=211$ ) participants' watched a 45 minute videotaped lecture. Participants were divided over three conditions: they were either instructed to simply watch the lecture, to take notes during the lecture, or they were asked reflective questions on the lecture content. The lecture was divided into several sections and after each section participants were given test like questions on the preceding lecture section. Afterwards participants' memory for the lecture content was tested with 26 short-answer items. Participants' memory ability was measured with a short-term memory test and remembrance of a short prose passage. The data revealed a different relationship between the note-taking conditions and performance on the short-answer test depending on participants' memory scores. The participants who scored higher 
on the memory tests scored higher on the short-answer test when they had taken notes during the video lecture. The participants who scored lower on the memory test, scored higher on the shortanswer test when they had been asked reflective questions. No note-taking was least beneficial for all participants. A possible explanation is that those with higher memory scores were able to deal with the simultaneous cognitive load of the lecture and note-taking, while those with lower memory scores were hindered by the simultaneous activity and thus benefitted more from reflective questions sequential to the lecture.

This result has further been explored in several studies (Kiewra \& Benton, 1988; Kiewra et al., 1987; Peverly et al., 2007). These studies consistently show that the magnitude of the encoding effect partly depends on individual differences in working memory ability. These individual studies are described and integrated clearly in a review by Bui and Myerson (2014), and we refer the interested reader to this review article. Overall it can be concluded that cognitive ability is an important moderator for the relationship between note-taking and memory for lecture content. Not only may those with better memory performance take better quality notes and thereby benefit more from their note-taking (Kiewra \& Benton, 1988; Kiewra et al., 1987; Peverly et al., 2007), those with lower memory performance and math ability may not even benefit from note-taking at all (Berliner, 1971; Peper \& Mayer, 1978). These moderating factors should be taken into account when advising students whether they should or should not take notes during their lectures.

\subsection{Testing procedure and note review}

In the studies conducted by Peper and Mayer (1978) math ability did not influence the relationship between note-taking and test performance for interpretation questions, but for factual questions high and low math ability showed different results. This highlights the importance of the type of test used to measure memory for lecture content. Mueller and Oppenheimer (2014, 
study 3) also found different effects based on the type of questions asked. While higher levels of verbatim overlap were related to lower performance on both factual and interpretation questions, this effect was stronger for interpretation than for factual questions.

An even stronger effect of test format was found by Barrett and colleagues (2014). In their experiment participants watched a 15 minute lecture on APA style formatting. Afterwards, participants were tested with 20 free response questions which either had to be answered on a computer or with handwriting. Results showed a significant interaction effect. Those for which the note-taking and testing procedures were congruent (i.e., both writing or both typing) scored better on the free response test than participants in the incongruent conditions.

When looking at the effects of note-taking on memory performance, not only the type of test can influence the results found, but also the timing of that test. Bui and colleagues (2013, study $2, n=76$ ) compared performance on a free recall test in an experiment with a $2 \times 2$ design. Students were instructed to take organised or transcribed notes, and half of students was administered the test immediately after the 11 minute lecture, while the other half of students was administered the test 24 hours later. When administering the test immediately after the 11 minute lecture, performance was best with transcribed notes compared to the organised notes. When the test was delayed 24 hours after the end of the lecture, performance was better for people who had taken organised notes.

The measures in and the timing of the memory test might thus influence the results in studies on the effect of note-taking on memory performance. Researchers should therefore carefully select their measures. As nearly nothing is known about the influence of the type and timing of the test on the relationship between the variables mentioned in this review (e.g., lecture format, style of note-taking, structure of note-taking) and memory for lecture content, further research is highly necessary. 


\section{Cognitive load}

In the preceding sections we have reviewed factors that influence the relationship between note-taking and memory for lecture content. Di Vesta and Gray (1972) provided two explanations as to why note-taking is beneficial for memory: The encoding effect and the external storage effect. The encoding effect explains why note-taking in and of itself is beneficial for memory. The external storage effect explains why reviewing notes is beneficial. However, the encoding and external storage effect cannot explain why note-taking is more or less beneficial in different settings, or with different methods of note-taking. In this section, we aim to use cognitive load theory (Plass, Moreno, \& Brünken, 2010) to explain why the effects of note-taking on memory for lecture content differ between individuals and different lecture conditions. In our view, many effects of note-taking on memory performance can be explained by the simple assumption that note-taking is cognitively effortful (Piolat, Olive, \& Kellogg, 2005). We can handle additional load until we reach our limit. If more load is present than we can handle, that is when our cognitive resources are unsatisfactory for the task at hand, performance will suffer. By analysing how much cognitive load people can handle, and measuring the amount of cognitive load induced by a specific task, we can make more fine-grained predictions about when note-taking improves performance on memory tests.

In order to be able to discuss the effects of note-taking on experienced cognitive effort, we distinguish five processes involved in note-taking (based on Bui \& Myerson, 2014; Kiewra, 1987; Peverly, 2006). When taking notes, a note-taker must (1) comprehend the lecture material, (2) identify key points, (3) link the material to prior knowledge and prior notes, (4) paraphrase or summarize, and (5) transform to written form (either by hand or by typing). As illustrated in Figure 1, the process is recursive, as the cycle is performed many times during a single lecture. Furthermore, it is possible that only parts of the cycle are performed, such as when one selects a 
key point, only to notice that it is already part of the notes and therefore does not need to be written down. One then continues comprehending the lecture until a new key point is identified.

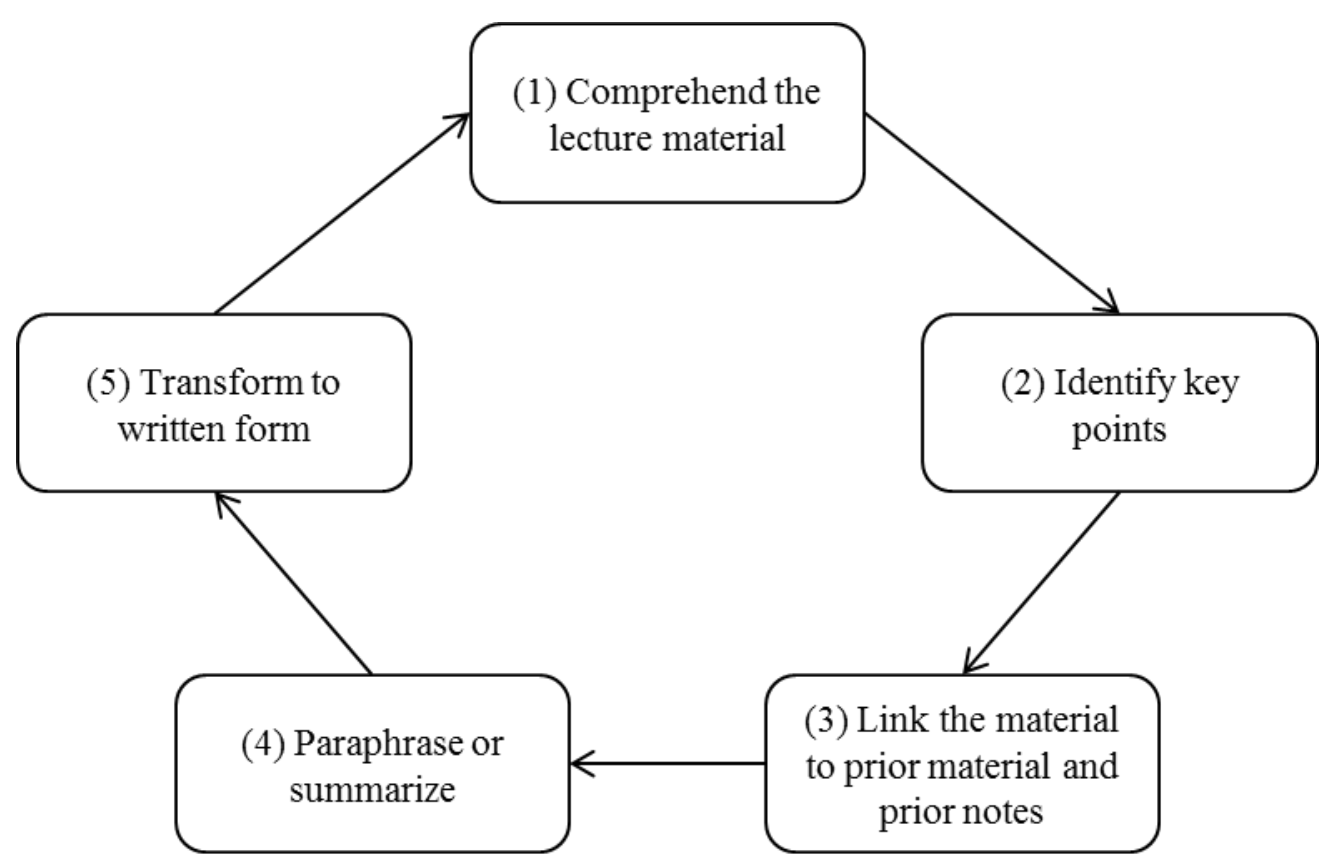

Figure 1 The five processes involved in taking notes while attending a lecture.

The first conclusion that can be drawn from this division into five processes is that notetaking induces more cognitive load than is required to just comprehend the lecture. While this might be obvious, it is important to note because it implies that people who don't take notes can expend all their mental resources on comprehending the lecture material. People who take notes have to divide their cognitive resources among four additional processes. The cognitive load induced by note-taking may lead to cognitive overload for some individuals in some situations, thereby making note-taking detrimental to memory performance, instead of beneficial. This may, at least in part, account for some of the variability in the findings across different studies reported in literature. In the next section we evaluate which influence each of the factors in Figure 1 may have on cognitive load. Our goal is to provide possible explanations for diverging effects that 
were observed in this review. By relating the different factors of note-taking to cognitive load, we try to integrate the highly diverse types of research done in note-taking research so far.

\subsection{Factors influencing cognitive effort expended}

A first factor discussed in this literature review is the structure of the lecture material presented. The structure of the material influences the amount of cognitive resources necessary to understand the material. Material that is less structured induces more cognitive load, not only because it is harder to comprehend, but also because it is more difficult to identify the key points.

The second research question in the literature pertained to the modality of the lecture material, a timely question now that video lectures are used more widely in university teaching. As video and live lectures contain interacting elements (e.g., images, text, sound; Sweller \& Chandler, 1994) that must be processed simultaneously, they induce more cognitive load than audio lectures. While trying to comprehend text lectures, students can take their notes and comprehend the lecture sequentially. Phases 2-5 thus no longer need to be performed at the same time as phase 1 . This makes the level of cognitive load induced by text lectures lower than for other lecture formats. In video lectures the amount of information presented while the student takes notes is dependent on the density of information in the lecture. High speed lectures or highly complex lectures contain more information in the same timeframe, and therefore students need to comprehend - and possibly miss - more information while taking notes.

Style of note-taking (i.e. longhand or typing) impacts the amount of information students must comprehend while making their notes. As typing is faster for most people than writing speed, there is less information presented in live or video lectures while typing notes compared to when people write their notes in longhand. When people would make the exact same notes, less effort is thus required during phase 5 (transform to written form) when typing than when using longhand. However, with a faster note-taking speed is also easier to keep up with the speed of the 
presenter. Typing notes may therefore lead to less paraphrasing and more verbatim overlap. Compared to writing, typing notes thereby not only leads to less effort expended on phase 5, but also on phase 4 (paraphrasing). On the one hand, this could have a positive result: more cognitive resources are available to focus on the lecture. On the other hand, this could also have a negative result: more verbatim overlap is associated with shallower processing and less encoding. Which effect is stronger should be explored in more detail and may likely be dependent on other aspects of the lecture and for instance note-taking structure.

When it comes to the specific structure of note-taking adopted by students, two notetaking structures were defined: An organised note-taking structure and a transcribing note-taking structure. When comparing these structures, differences appear in effort expended to linking key points to prior notes and paraphrasing. Taking organised notes requires more effort to link new information to prior notes and paraphrasing, as this is necessary to integrate the information that is presented. These aspects are not as important when transcribing notes, where the focus is on noting down as much as possible of what is presented. Effort expended on linking to prior notes and paraphrasing should thus be lower with transcribing than when organising notes. Based on this theoretical explanation, a different note-taking structure should lead to differences in the use of cognitive resources. This may also explain the different results of Bretzing and Kulhavy (1979) and Bui et al. (2013), who both compared organised and transcribed note-taking. As Bui et al. (2013) used an audio lecture, participants in the organised note-taking condition had to expend additional effort on phases 2 and 3 simultaneously to comprehending the lecture. This additional load likely was too high, as participants in the transcribed note-taking condition remembered the lecture content better than those in the organised note-taking condition. In the study of Bretzing and Kulhavy (1979) organised note-taking was beneficial compared to transcribed note-taking for memory of lecture content. In this study, however, a text lecture was 
used; the additional load on phases 2 and 3 with organised note-taking could thus be expended sequentially to comprehending the lecture.

Finally, we discussed individual differences in cognitive ability. Some studies found that students with higher cognitive abilities benefitted more from note-taking than students with lower cognitive abilities. Possible explanations for this finding are that students with larger memory capacity can deal with more cognitive load or that the different phases induce less cognitive load in them than in those with lower cognitive abilities. Other studies showed that note-taking even led to worse performance for those with lower cognitive abilities. It seems likely that note-taking induced more cognitive load than these participants could handle, reducing their ability to take good notes and process the lecture content, thereby reducing their memory for the content of the lecture. Without note-taking, they only had to deal with the cognitive load of processing the material itself, which lead to better performance.

It seems some diverging results in the literature review can be resolved by looking closely at differences between procedures used, and taking the amount of cognitive load that is induced into account. However, further research is warranted to test the effects of note-taking on cognitive load in general, and specifically of aspects of the lecture material, the note-taking method and individual differences.

\section{Conclusions}

We have reviewed and integrated research on the effects of note-taking on memory, and proposed cognitive load theory as a framework to understand the fragmented nature of the empirical findings. By dividing note-taking in five cognitive processes (see Figure 1), the experimental variables examined inliterature can be connected to one or more of these processes. This integration facilitates a better understanding of why experiments that look similar on first 
glance can lead to different results, and provides a useful stepping stone for future theory development and experimental work.

Our review highlights how fragmented the current research on note-taking is. Many aspects of note-taking have been examined, but none of these has been studied in enough detail to be able to draw strong conclusions. The diversity in manipulations and dependent variables often makes direct comparisons between studies difficult. We have explicitly mentioned sample sizes in this review to draw attention to the small sample sizes in many studies, especially when using between-subject designs, which lead to low statistical power. Although some main effects seem plausible and reasonably well-supported (e.g., cognitive ability moderating the effect of organizing or transcribing notes on memory for lecture content, or benefits of well-structured lectures), for many factors evidence is weak or inconclusive, and moderators or interactions between different factors remain unexamined.

The increasing popularity of video lectures warrants dedicated attention in future studies. While video lectures have the opportunity to incorporate moving images and have the benefit for memory of presenting information through two sensory modalities (i.e., visually and auditory), they also allow students to pause the video while taking notes, without having to spend cognitive resources on comprehending the lecture content at the same time, as is required in live lectures. Video lectures thus have the potential to make note-taking beneficial for all students, regardless of their cognitive ability.

Note-taking is behavior which is performed regularly, especially in educational settings. Our review suggests note-taking may not always be beneficial, and depends on the way lectures are presented, how notes are taken, and individual differences in cognitive abilities. We suggest that note-taking is a multi-stage process, where each stage may impose cognitive load, which can subsequently affect the availability of cognitive resources required for processing and memory 
encoding of the target material. This unifying framework of note-taking helps in understanding the variance in results between different studies reported in literature. Due to the widespread practice of note-taking, and the potential benefits of note-taking for memory, it is worthwhile to generate reliable knowledge on this topic, using high-powered studies that examine underlying cognitive mechanisms in light of a larger theoretical framework. 


\section{References}

Aiken, E. G., Thomas, G. S., \& Shennum, W. A. (1975). Memory for a lecture: Effects of notes, lecture rate, and informational density. Journal of Educational Psychology, 67(3), 439444. https://doi.org/10.1037/h0076613

Barnett, J. E., Di Vesta, F. J., \& Rogozinski, J. T. (1981). What is learned in note taking? Journal of Educational Psychology, 73(2), 181-192. https://doi.org/10.1037/0022-0663.73.2.181

Barrett, M. E., Swan, A. B., Mamikonian, A., Ghajoyan, I., Kramarova, O., \& Youmans, R. J. (2014). Technology in Note Taking and Assessment: The Effects of Congruence on Student Performance. International Journal of Instruction, 7(1), 51-60.

Berliner, D. C. (1971). Aptitute-treatment interactions in two studies of learning form lecture instruction. Presented at the American Educational Research Association, New York City.

Bretzing, B. H., \& Kulhavy, R. W. (1979). Notetaking and Depth of Processing. Contemporary Educational Psychology, 4, 145-153.

Bui, D. C., \& McDaniel, M. A. (2015). Enhancing learning during lecture note-taking using outlines and illustrative diagrams. Journal of Applied Research in Memory and Cognition, 4(2), 129-135. https://doi.org/10.1016/j.jarmac.2015.03.002

Bui, D. C., \& Myerson, J. (2014). The role of working memory abilities in lecture note-taking. Learning and Individual Differences, 33, 12-22.

https://doi.org/10.1016/j.lindif.2014.05.002

Bui, D. C., Myerson, J., \& Hale, S. (2013). Note-Taking With Computers: Exploring Alternative Strategies for Improved Recall. Journal of Educational Psychology, 105(2), 299-309. https://doi.org/10.1037/a0030367

Carter, J. F., \& Van Matre, N. H. (1975). Note Taking Versus Note Having. Journal of Educational Psychology, 67(6), 900-904. 
Christopoulos, J. P., Rohwer, W. D., \& Thomas, J. W. (1987). Grade level differences in students' study activities as a function of course characteristics. Contemporary Educational Psychology, 12(4), 303-323. https://doi.org/10.1016/S0361-476X(87)800036

Daneman, M., \& Carpenter, P. A. (1980). Individual differences in working memory and reading. Journal of Verbal Learning and Verbal Behavior, 19(4), 450-466. https://doi.org/10.1016/S0022-5371(80)90312-6

Di Vesta, F. J., \& Gray, G. S. (1972). Listening and note taking. Journal of Educational Psychology, 63(1), 8-14.

Di Vesta, F. J., \& Gray, G. S. (1973). Listening and note taking: II. Immediate and delayed recall as functions of variations in thematic continuity, note taking, and length of listeningreview intervals. Journal of Educational Psychology, 64(3), 278-287. https://doi.org/10.1037/h0034589

Einstein, G. O., Morris, J., \& Smith, S. (1985). Note-taking, individual differences, and memory for lecture information. Journal of Educational Psychology, 77(5), 522-532. https://doi.org/10.1037/0022-0663.77.5.522

Fisher, J. L., \& Harris, M. B. (1973). Effect of note taking and review on recall. Journal of Educational Psychology, 65(3), 321-325.

Graham, S., Berninger, V., Weintraub, N., \& Schafer, W. (1998). Development of Handwriting Speed and Legibility in Grades 1-9. The Journal of Educational Research, 92(1), 42-52. https://doi.org/10.1080/00220679809597574

Just, M. A., \& Carpenter, P. A. (1992). A capacity theory of comprehension: Individual differences in working memory. Psychological Review, 99(1), 122-149. https://doi.org/10.1037/0033-295X.99.1.122 
Katayama, A. D., \& Robinson, D. H. (2000). Getting Students "Partially" Involved in NoteTaking Using Graphic Organizers, 68(2), 119-133. https://doi.org/10.1080/00220970009598498

Kauffman, D. F., Zhao, R., \& Yang, Y.-S. (2011). Effects of online note taking formats and selfmonitoring prompts on learning from online text: Using technology to enhance selfregulated learning. Contemporary Educational Psychology, 36(4), 313-322. https://doi.org/10.1016/j.cedpsych.2011.04.001

Kiewra, K. A. (1985). Students' Note-Taking Behaviors and the Efficacy of Providing the Instructor's Notes for Review. Contemporary Educational Psychology, 10, 378-386.

Kiewra, K. A. (1987). Notetaking and review: The research and its implications. Instructional Science, 16(3), 233-249. https://doi.org/10.1007/BF00120252

Kiewra, K. A. (1989). A review of note-taking: The encoding-storage paradigm and beyond. Educational Psychology Review, 1(2), 147-172. https://doi.org/10.1007/BF01326640

Kiewra, K. A., \& Benton, S. L. (1988). The Relationship between Information-Processing Ability and Notetaking. Contemporary Educational Psychology, 13, 33-44.

Kiewra, K. A., Benton, S. L., \& Lewis, L. B. (1987). Qualitative Aspects of Notetaking and Their Relationship with Information-Processing Ability and Academic Achievement. Journal of Instructional Psychology, 14(3), 110-117.

Lin, L., \& Bigenho, C. (2011). Note-Taking and Memory in Different Media Environments. Computers in the Schools: Interdisciplinary Journal of Practice, Theory, and Applied Research, 28(3), 200-216. https://doi.org/10.1080/07380569.2011.594989

Mueller, P. A., \& Oppenheimer, D. M. (2014). The Pen Is Mightier Than the Keyboard: Advantages of Longhand Over Laptop Note Taking. Psychological Science, 25(6), 11591168. https://doi.org/10.1177/0956797614524581 
Peper, R. J., \& Mayer, R. E. (1978). Note taking as a generative activity. Journal of Educational Psychology, 70(4), 514-522. https://doi.org/10.1037/0022-0663.70.4.514

Peper, R. J., \& Mayer, R. E. (1986). Generative effects of note-taking during science lectures. Journal of Educational Psychology, 78(1), 34-38. https://doi.org/10.1037/00220663.78 .1 .34

Pereira, A., Lee, D. L., Sadeeshkumar, H., Laroche, C., Odell, D., \& Rempel, D. (2013). The Effect of Keyboard Key Spacing on Typing Speed, Error, Usability, and Biomechanics: Part 1. Human Factors: The Journal of the Human Factors and Ergonomics Society, 55(3), 557-566. https://doi.org/10.1177/0018720812465005

Peters, D. L. (1972). Effects of note taking and rate of presentation on short-term objective test performance. Journal of Educational Psychology, 63(3), 276-280. https://doi.org/10.1037/h0032647

Peverly, S. T. (2006). The Importance of Handwriting Speed in Adult Writing. Developmental Neuropsychology, 29(1), 197-216. https://doi.org/10.1207/s15326942dn2901_10

Peverly, S. T., Ramaswamy, V., Brown, C., Sumowski, J. F., Alidoost, M., \& Garner, J. (2007). What Predicts Skill in Lecture Note Taking? Journal of Educational Psychology, 99(1), 167-180. https://doi.org/10.1037/0022-0663.99.1.167

Peverly, S. T., \& Sumowski, J. F. (2012). What Variables Predict Quality of Text Notes and are Text Notes Related to Performance on Different Types of Tests?: Text notetaking. Applied Cognitive Psychology, 26(1), 104-117. https://doi.org/10.1002/acp.1802

Peverly, S. T., Vekaria, P. C., Reddington, L. A., Sumowski, J. F., Johnson, K. R., \& Ramsay, C. M. (2013). The Relationship of Handwriting Speed, Working Memory, Language Comprehension and Outlines to Lecture Note-taking and Test-taking among College 
Students: Cognitive processes and note-taking. Applied Cognitive Psychology, 27(1), 115-126. https://doi.org/10.1002/acp.2881

Piolat, A., Olive, T., \& Kellogg, R. T. (2005). Cognitive Effort during Note Taking. Applied Cognitive Psychology, 19, 291-312. https://doi.org/10.1002/acp.1086

Plass, J. L., Moreno, R., \& Brünken, R. (2010). Cognitive load theory. Cambridge University Press.

Reimer, Y. J., Brimhall, E., Cao, C., \& O’Reilly, K. (2009). Empirical user studies inform the design of an e-notetaking and information assimilation system for students in higher education. Computers \& Education, 52(4), 893-913. https://doi.org/10.1016/j.compedu.2008.12.013

Schoen, I. (2012). Effects of Method and Context of Note-taking on Memory: Handwriting versus Typing in Lecture and Textbook-Reading Contexts. Pitzer Senior Theses, (Paper 20). Retrieved from http://scholarship .claremont.edu/pitzer_theses/20

Shrager, L., \& Mayer, R. E. (1989). Note-taking fosters generative learning strategies in novices. Journal of Educational Psychology, 81(2), 263-264. https://doi.org/10.1037/00220663.81 .2 .263

Sweller, J., \& Chandler, P. (1994). Why Some Material Is Difficult to Learn. Cognition and Instruction, 12(3), 185-233.

Titsworth, B. S., \& Kiewra, K. A. (2004). Spoken organizational lecture cues and student notetaking as facilitators of student learning. Contemporary Educational Psychology, 29(4), 447-461. https://doi.org/10.1016/j.cedpsych.2003.12.001

Weiland, A., \& Kingsbury, S. T. (1979). Immediate and Delayed Recall of Lecture Material as a Function of Note Taking. The Journal of Educational Research, 72(4), 229-230. 


\begin{tabular}{|c|c|c|c|c|c|c|c|c|c|}
\hline $\begin{array}{l}\text { Author } \\
\text { (year) }\end{array}$ & Study & $\mathbf{N}$ & Design & Conditions & $\begin{array}{l}\text { Lecture } \\
\text { modality }\end{array}$ & Test & $\begin{array}{l}\text { Review } \\
\text { condition } \\
\text { included? }\end{array}$ & $\begin{array}{l}\text { Memory } \\
\text { measure } \\
\text { included? }\end{array}$ & $\begin{array}{l}\text { Note } \\
\text { content } \\
\text { analyzed? }\end{array}$ \\
\hline $\begin{array}{l}\text { Aiken, } \\
\text { Thomas \& } \\
\text { Shennum } \\
\text { (1975) }\end{array}$ & & 180 & $\begin{array}{l}\text { Between } \\
(3 \times 3 \times 2)\end{array}$ & $\begin{array}{l}\text { Note-taking } \mathrm{x} \text { lecture speed } \mathrm{x} \\
\text { information density lecture }\end{array}$ & Audio & $\begin{array}{l}\text { Free recall + } \\
\text { recognition } \\
\text { memory }\end{array}$ & No & No & Yes \\
\hline $\begin{array}{l}\text { Barrett et al. } \\
(2014)\end{array}$ & & 79 & $\begin{array}{l}\text { Between } \\
(2 \times 2)\end{array}$ & Note-taking style $\mathrm{x}$ test style & Video & Open questions & No & No & No \\
\hline \multirow[t]{2}{*}{$\begin{array}{l}\text { Berliner } \\
(1971)\end{array}$} & 1 & 211 & $\begin{array}{l}\text { Between } x \\
\text { within } \\
(5 \times 2)\end{array}$ & Note-taking $\mathrm{x}$ timing of test & Video & Short answer & Yes & Yes & No \\
\hline & 2 & 211 & $\begin{array}{l}\text { Between } x \\
\text { within } \\
(3 \times 2)\end{array}$ & Note-taking $\mathrm{x}$ timing of test & Video & Short answer & Yes & Yes & No \\
\hline $\begin{array}{l}\text { Bretzing \& } \\
\text { Kulhavy } \\
\text { (1979) }\end{array}$ & & 180 & $\begin{array}{l}\text { Between } \\
(4 \times 2)\end{array}$ & $\begin{array}{l}\text { Structure of note-taking } \mathrm{x} \text { note- } \\
\text { review x timing of test }\end{array}$ & Text & Short answer & Yes & No & No \\
\hline $\begin{array}{l}\text { Bui \& } \\
\text { McDaniel } \\
(2015)\end{array}$ & & 144 & $\begin{array}{l}\text { Between } \\
\text { (3) }\end{array}$ & Learning aid & Audio & $\begin{array}{l}\text { Free recall }+ \text { short } \\
\text { answer }\end{array}$ & No & Yes & No \\
\hline \multirow{3}{*}{$\begin{array}{l}\text { Bui, Myerson } \\
\& \text { Hale } \\
(2013)\end{array}$} & 1 & 80 & $\begin{array}{l}\text { Between } \\
(2 \times 2)\end{array}$ & $\begin{array}{l}\text { Structure of note-taking } \mathrm{x} \text { note- } \\
\text { taking style }\end{array}$ & Audio & $\begin{array}{l}\text { Free recall }+ \text { short } \\
\text { answer }\end{array}$ & No & No & Yes \\
\hline & 2 & 76 & $\begin{array}{l}\text { Between } \\
(2 \times 2)\end{array}$ & $\begin{array}{l}\text { Structure of note-taking } \mathrm{x} \text { timing of } \\
\text { test }\end{array}$ & Audio & $\begin{array}{l}\text { Free recall }+ \text { short } \\
\text { answer }\end{array}$ & No & No & Yes \\
\hline & 3 & 72 & $\begin{array}{l}\text { Between } \\
(2 \times 2)\end{array}$ & $\begin{array}{l}\text { Structure of note-taking x note- } \\
\text { review }\end{array}$ & Audio & $\begin{array}{l}\text { Free recall }+ \text { short } \\
\text { answer }\end{array}$ & Yes & No & Yes \\
\hline $\begin{array}{l}\text { Di Vesta \& } \\
\text { Gray (1972) }\end{array}$ & & 120 & $\begin{array}{l}\text { Between } \\
(2 \times 2)\end{array}$ & $\begin{array}{l}\text { Note-taking } \mathrm{x} \text { note-review } \mathrm{x} \text { filler } \\
\text { task }\end{array}$ & Audio & Free recall $+\mathrm{MC}$ & Yes & No & No \\
\hline \multirow[t]{2}{*}{$\begin{array}{l}\text { Di Vesta \& } \\
\text { Gray (1973) }\end{array}$} & 1 & 90 & $\begin{array}{l}\text { Between } \\
(2 \times 3 \times 3)\end{array}$ & $\begin{array}{l}\text { Note-taking x relatedness of } \\
\text { segments x segment length }\end{array}$ & Audio & $\begin{array}{l}\text { Free recall }+ \\
\text { true/false }\end{array}$ & No & Yes & No \\
\hline & 2 & 240 & $\begin{array}{l}\text { Between } \\
(2 \times 4 \times 3)\end{array}$ & $\begin{array}{l}\text { Note-taking x relatedness of } \\
\text { segments x segment length }\end{array}$ & Audio & $\begin{array}{l}\text { Free recall + } \\
\text { true/false }\end{array}$ & No & Yes & No \\
\hline
\end{tabular}




\begin{tabular}{|c|c|c|c|c|c|c|c|c|}
\hline $\begin{array}{l}\text { Einstein, } \\
\text { Morris \& } \\
\text { Smith (1985) }\end{array}$ & 1 & 48 & $\begin{array}{l}\text { Between } \\
(2)\end{array}$ & Note-taking & Video & Free recall & No & No \\
\hline & 2 & 96 & $\begin{array}{l}\text { Between } \\
(2 \times 2 \times 2)\end{array}$ & $\begin{array}{l}\text { Student ability } x \text { note-review } \mathrm{x} \\
\text { timing of test }\end{array}$ & Video & Free recall & Yes & No \\
\hline $\begin{array}{l}\text { Fisher \& } \\
\text { Harris (1973) }\end{array}$ & & 112 & $\begin{array}{l}\text { Between } \\
(2 \times 3)\end{array}$ & Note-taking $\mathrm{x}$ note-review & Live & $\begin{array}{l}\text { Free recall }+\mathrm{MC}+ \\
\text { short answer }\end{array}$ & Yes & No \\
\hline $\begin{array}{l}\text { Katayama \& } \\
\text { Robinson } \\
(2000)\end{array}$ & & 117 & $\begin{array}{l}\text { Between } \\
(2 \times 3)\end{array}$ & $\begin{array}{l}\text { Structure of note-taking } \mathrm{x} \text { content of } \\
\text { notes }\end{array}$ & Text & $\begin{array}{l}\text { Factual + } \\
\text { application } \\
\text { knowledge }\end{array}$ & Yes & No \\
\hline $\begin{array}{l}\text { Kauffman, } \\
\text { Zhao \& Yang }\end{array}$ & 1 & 30 & $\begin{array}{l}\text { Between } \\
\text { (3) }\end{array}$ & Structure of note-taking & Text & $\mathrm{MC}+$ short answer & Yes & No \\
\hline & 2 & 119 & $\begin{array}{l}\text { Between } \\
(3 \times 2)\end{array}$ & Structure of note-taking x prompts & Text & $\begin{array}{l}\text { Declarative + } \\
\text { procedural + } \\
\text { application } \\
\text { knowledge }\end{array}$ & Yes & No \\
\hline $\begin{array}{l}\text { Kiewra } \\
(1985)\end{array}$ & & 17 & $\begin{array}{l}\text { Between } x \\
\text { within } \\
(2 \times 2)\end{array}$ & Note-taking $\mathrm{x}$ timing of test & Video & $\begin{array}{l}\text { Factual }+ \text { transfer } \\
\text { knowledge }(\mathrm{MC})\end{array}$ & Yes & No \\
\hline $\begin{array}{l}\text { Kiewra \& } \\
\text { Benton } \\
(1988)\end{array}$ & & 32 & Between & No manipulations & Video & $\begin{array}{l}\text { MC factual + } \\
\text { application } \\
\text { knowledge }\end{array}$ & Yes & Yes \\
\hline $\begin{array}{l}\text { Kiewra, } \\
\text { Benton \& } \\
\text { Lewis (1987) }\end{array}$ & & 55 & Between & No manipulations & Live & $\begin{array}{l}\text { Lecture test }+ \\
\text { course exam }\end{array}$ & Yes & Yes \\
\hline $\begin{array}{l}\text { Mueller \& } \\
\text { Oppenheimer } \\
\text { (2014) }\end{array}$ & 1 & 65 & $\begin{array}{l}\text { Between } \\
\text { (2) }\end{array}$ & Note-taking style & Video & $\begin{array}{l}\text { Factual + } \\
\text { application } \\
\text { knowledge }\end{array}$ & No & No \\
\hline & 2 & 149 & $\begin{array}{l}\text { Between } \\
\text { (3) }\end{array}$ & Note-taking style & Video & $\begin{array}{l}\text { Factual + } \\
\text { application } \\
\text { knowledge }\end{array}$ & No & No \\
\hline & 3 & 109 & $\begin{array}{l}\text { Between } \\
(2 \times 2)\end{array}$ & Note-taking style $\mathrm{x}$ note-review & Video & $\begin{array}{l}\text { Factual }+ \\
\text { application }\end{array}$ & Yes & No \\
\hline
\end{tabular}




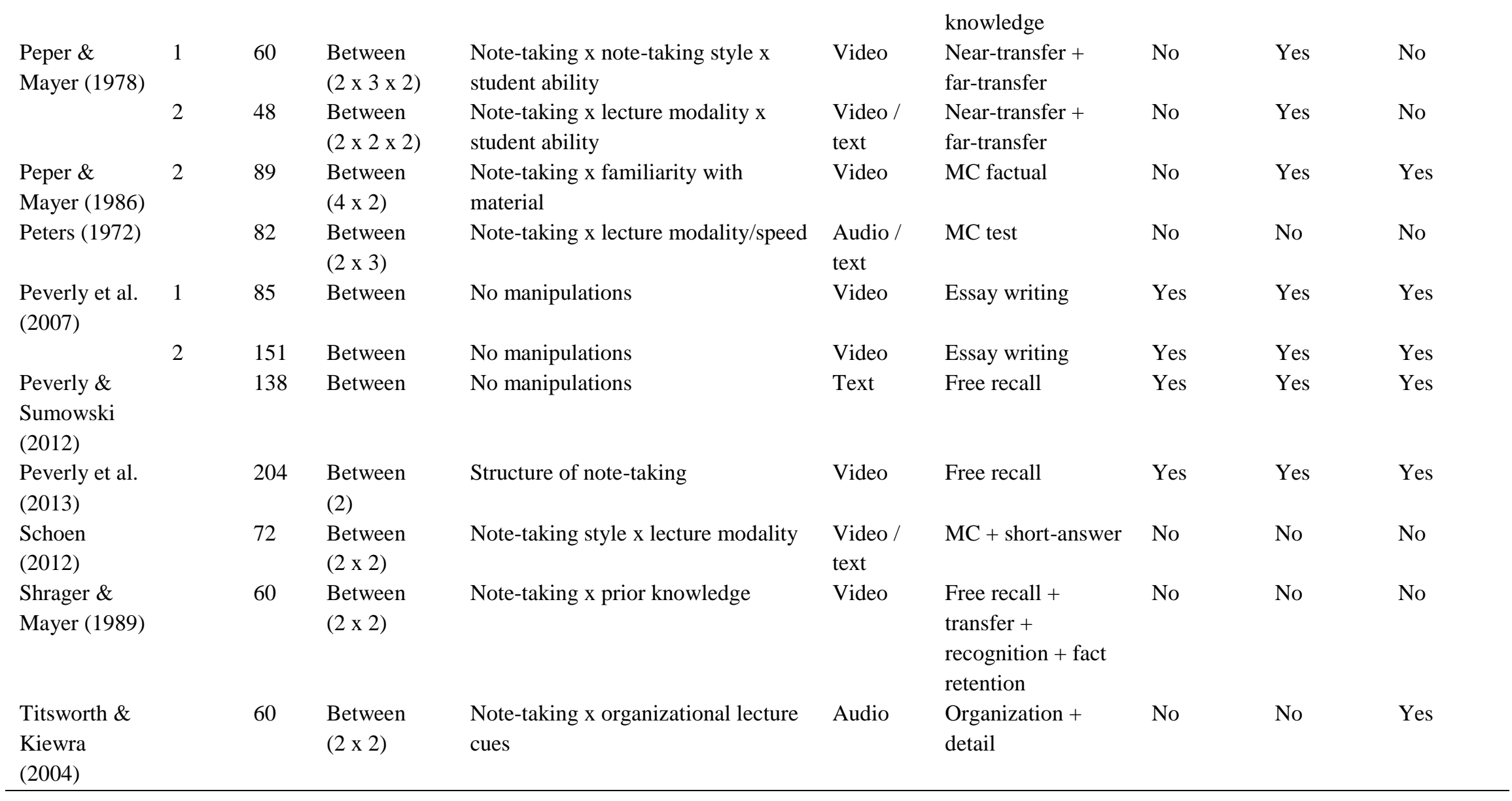

